\title{
SISTEM NETT ZERO ENERGY BUILDING PADA RUSUNAWA
}

\author{
Anisa Yusita Pratama ${ }^{1)}$, Rudy Trisno ${ }^{2)}$ \\ 1)Program Studi S1 Arsitektur, Fakultas Teknik, Universitas Tarumanagara, anisayusita@gmail.com \\ 2) Program Studi S1 Arsitektur, Fakultas Teknik, Universitas Tarumanagara, rudyt@ft.untar.ac.id
}

Masuk: 04-07-2021, revisi: 14-08-2021, diterima untuk diterbitkan: 23-10-2021

\begin{abstract}
Abstrak
Setiap tahun terjadi peningkatan jumlah penduduk di Kota Jakarta hal ini mengakibatkan penggunaan lahan untuk bangunan semakin meningkat karena terjadi peningkatan kebutuhan ruang kota. Tingginya laju pertumbuhan penduduk menimbulkan kebutuhan lahan permukiman yang sangat besar. Hal ini tidak seimbang dengan luas lahan yang dimiliki Jakarta. Dengan keterbatasan ini memicu dan mengakibatkan banyaknya hunian semi permanen di pusat kota dan sebagian membentuk hunian kumuh di beberapa tempat. Selain itu, dengan terjadinya pandemi mempengaruhi kebiasaan baru pada manusia yang membuat masyarakat lebih peka terhadap faktor kesehatan sebagai respons atas kondisi pandemi. Salah satunya yaitu terdapat fenomena baru yang terjadi di masyarakat kota seperti banyaknya yang bercocok tanam di hunian, untuk memiliki rumah yang sehat. Proyek ini bertujuan untuk memenuhi kriteria rumah atau pemukiman yang sehat untuk penghuni dan sekitarnya serta dapat mengakomodasi kebutuhan akan hunian layak dan terjangkau di masyarakat khususnya untuk MBR. Metode yang digunakan yaitu dengan ekologi dan net zero building dengan bantuan aplikasi EDGE. Kesimpulan akhirnya adalah proyek ini dimaksudkan untuk menjadi hunian vertikal yang sehat, nyaman dan aman di lahan yang terbatas.
\end{abstract}

Kata kunci: Bangunan; Edge; Mbr; Nzeb; Rusunawa

\begin{abstract}
Every year there is an increase in the number of residents in the city of Jakarta, this causes the use of land for buildings to increase due to an increase in the need for urban space. The high rate of population growth raises the need for very large residential land. This is not balanced with the land area owned by Jakarta. With these limitations triggered and resulted in the number of semi-permanent housing in the city center and some forming slum areas in some places. In addition, pandemic which affects new habits in humans, which makes people more sensitive to health factors in responding to pandemic conditions. One of them is a new phenomenon that occurs in urban communities, such as many who grow crops in their homes, to have a healthy home. This project aims to meet the criteria for a healthy house or settlement for residents and their surroundings and can accommodate new needs in the community, especially for MBR. The method used ecology architecture and net zero building with EDGE app. The final conclusion is that this project is intended to be a healthy, comfortable and safe vertical residence in a limited area.
\end{abstract}

\section{Keywords: Building; Edge; Nzeb; Rusunawa}

\section{PENDAHULUAN}

Kebijakan tata ruang yang bisa meningkatkan kepadatan adalah jawaban untuk mengatasi krisis hunian dan menjadikan hunian vertikal di tengah kota terjangkau. Pemerintah DKI Jakarta yang memegang kendali Rencana Detail Tata Ruang (RDTR) adalah pemeran utamanya. Selain itu, hal tersebut akan menimbulkan urban sprawl atau pemekaran kota ke daerah-daerah di sekitarnya secara tidak terstruktur, dan penyakit urban lainnya seperti kemacetan dan polusi. (Wilfridus Setu Embu, n.d.) 
Selain itu, yang menjadi masalah utama di kota besar tidak tersedia rumah yang cukup dengan jumlah yang memadai dan terjangkau bagi masyarakat berpenghasilan rendah dan miskin termasuk kurangnya akses sarana transportasi umum yang murah, aman, dan layak serta pelayanan air minum yang memadai, sehingga tinggal di permukiman kumuh menjadi satusatunya pilihan di kota besar. (Soeranto, Dwityo A., 2020)

Mengikuti perkembangan dalam pembangunan yang mengarah kepada ramah lingkungan Indonesia diharapkan dapat bisa menerapkan bangunan hemat energi di 2030 sesuai dengan ketentuan aturan Environmental Protection Agency (EPA) (Direktorat Jenderal Energi Baru, Terbarukan dan Konservasi Energi, 2020)

Berdasarkan data terbaru dari Dinas Kependudukan dan Pencatatan Sipil, jumlah penduduk DKI Jakarta tahun 2019 mencapai 11.063.324 jiwa. Sementara itu, luas DKI Jakarta adalah 662,33 $\mathrm{km}^{2}$ menurut Keputusan Gubernur No 171 Tahun 2007. Berarti, kepadatan penduduk DKI Jakarta saat ini mencapai $16.704 \mathrm{jiwa} / \mathrm{km}^{2}$. Bila kita keluarkan Kepulauan Seribu dari perhitungan, maka kepadatan penduduk DKI Jakarta di wilayah perkotaan menjadi 16.882 $\mathrm{jiwa} / \mathrm{km}^{2}$. Bandingkan dengan kepadatan penduduk Indonesia yang hanya $141 \mathrm{jiwa} / \mathrm{km}^{2}$ (hasil dari proyeksi penduduk tahun 2020 dibagi dengan luas daratan Indonesia). (Adhitya Akbar, n.d.)

Lokasi yang menjadi fokus utama untuk pembangunan rumah susun ini adalah di Jakarta Timur, karena Jakarta Timur memiliki kepadatan yang tinggi dan juga memiliki RTDR untuk pembangunan rumah vertikal yang cukup banyak. Untuk kepadatan Penduduk Jakarta Timur yaitu rata-rata sekitar 12.507 per $\mathrm{km}^{2}$. Alasan tersebut yang membuat Lokasi Jl. Perumahan Jatinegara Indah no. 14, Cakung, Jakarta Timur dengan luas tapak 18.000 m2.

\section{KAJIAN LITERATUR}

\section{Hunian}

Kebutuhan akan rumah adalah salah satu kebutuhan yang paling penting bagi manusia selain kebuthan lainnya. Rumah merupakan tempat dimana tempat awal kehidupan keluarga berlindung dan mempunyai fungsi sebagai pusat pendidikan, adat budaya serta merupakan representasi dari pemiliknya.

Maka dari itu terbit UU Tentang Perumahan dan Permukiman yaitu UU no.1 tahun 2011 yang antara lain mendefinisikan beberapa konsep sebagai berikut :

a. Perumahan dan Kawasan Permukiman adalah satu kesatuan sistem yang terdiri atas pembinaan, penyelenggaraan perumahan, penyelenggaraan kawasan permukiman, pemeliharaan dan perbaikan, pencegahan dan peningkatan kualitas terhadap perumahan kumuh dan permukiman kumuh, penyediaan tanah, pendanaan dan sistem pembiayaan, serta peran masyarakat.

b. Perumahan adalah kumpulan rumah sebagai bagian dari permukiman, baik perkotaan maupun perdesaan, yang dilengkapi dengan prasarana, sarana, dan utilitas umum sebagai hasil upaya pemenuhan rumah yang layak huni.

c. Kawasan Permukiman adalah bagian dari lingkungan hidup di luar kawasan lindung, baik berupa kawasan perkotaan maupun perdesaan, yang berfungsi sebagai lingkungan tempat tinggal atau lingkungan hunian dan tempat kegiatan yang mendukung perikehidupan dan penghidupan.

Beberapa pengertian umum mengenai rumah susun berdasarakan peraturan Menteri Negara Perumahan Rakyat No.5 tahun 2007 Mengenai Pedoman Teknis Pembangunan Rumah Susun Sederhana Bertingkat Tinggi adalah sebagai berikut: 
a. Rumah Susun adalah bangunan gedung bertingkat yang dibangun dalam suatu lingkungan yang terbagi dalam bagian-bagian yang distrukturkan secara fungsional dalam arah horizontal maupun vertikal dan merupakan satuan-satuan yang masing-masing dapat dimiliki dan digunakan secara terpisah, yang berfungsi untuk tempat hunian, yang dilengkapi dengan bagian bersama, benda bersama dan tanah bersama.

b. Satuan Rumah Susun (Sarusun) adalah unit hunian rumah susun yang dihubungkan dan mempunyai akses ke selasar/koridor/lobi dan lantai lainnya dalam bangunan rumah susun, serta akses ke lingkungan dan jalan umum.

c. Prasarana dan Sarana Rumah Susun adalah kelengkapan dasar fisik lingkungan yang memungkinkan lingkungan rumah susun dapat berfungsi sebagaimana mestinya, yang antara lain berupa jaringan jalan dan utilitas umum, jaringan pemadam kebakaran tempat sampah, parkir, saluran drainase, tangki septik, sumur resapan, rambu penuntun dan lampu penerangan luar.

d. Rumah Susun Sederhana (Rusuna) adalah rumah susun yang diperuntukan bagi masyarakat berpenghasilan menengah bawah dan berpenghasilan rendah.

e. Masyarakat Berpenghasilan Rendah adalah masyarakat yang mempunyai pendapatan diatas Rp. 1.000.000,- sampai dengan Rp. 2.500.000,- per bulan, atau yang ditetapkan oleh Menteri Negara Perumahan Rakyat.

f. Rusuna Bertingkat Tinggi adalah bangunan gedung rumah susun sederhana dengan jumlah lantai bangunan lebih dari 8 lantai dan maksimum 20 lantai.

\section{Pengertian NZEB}

Secara umum, Zero-Energy Building (ZEB) adalah suatu konsepsi di mana bangunan yang mengimplementasikan tema ini menjadi suatu bangunan mandiri yang secara keseluruhan (Net) dapat membuat dan menghasilkan energinya sendiri. Energi yang dihasilkan memiliki jumlah yang sama atau lebih dari jumlah energi yang digunakan bangunan tersebut.

\section{Prinsip Zero-Energy Building (ZEB)}

Prinsip dari perancangan yang menggunakan konsep Zero-Energy Building ini adalah mengatasi permasalahan lingkungan yang ditimbulkan dalam bidang arsitektural serta menghilangkan ketergantungan penggunaan energi yang bersumber dari energi tak terbarukan (Unrenewable Energy) dan lebih menggunakan energi terbarukan (Renewable Energy).

\section{Interpretasi Arsitektural}

Selain menggunakan tema Zero-Energy Building (ZEB), perancangan ini menggunakan pendekatan perancangan Bangunan Pintar (Smart Building).

Metodologi ZNEB mengikuti empat langkah menyeluruh terhadap pengurangan energi, yaitu meminimalkan beban bangunan (passive strategy), memaksimalkan efisiensi energi (strategi aktif dengan mekanik, listrik, dan sistem pipa), menghasilkan energi terbarukan dan mengurangi konsumsi energi dari sebuah bangunan. Dari empat langkah ini, penting untuk memahami bahwa tiga pertama didorong oleh keputusan desain, sementara langkah keempat didefinisikan oleh keputusan operasional.

Pada review jurnal yang berjudul A Zero Net Energy Building Pilot Study yang dilakukan oleh Jordan dan Yanel, menyebutkan bahwa Zero Net Energy Building (ZNEB) memiliki 4 tahap proses, yaitu:

Design :

a. Minimize Building Loads

b. Maximize Energy Efficiency

c. Utilize On-Site Renewable Energy Production 
Operational :

Minimize Building Energy Consumption (Magdalena \& Tondobala, 2016)

Panel Surya

Panel Surya adalah alat konversi energi cahaya matahari menjadi energi listrik. Untuk memanfaatkan potensi energi surya ada dua macam teknologi yang sudah diterapkan, yaitu energi surya fotovoltaik dan energi surya termal (Purwoto, Jatmiko, Alimul , \& Huda)

Manfaat Panel Surya Terdapat banyak manfaat jika memasang panel surya sebagai pembangkit listrik alternatif. Dalam buku Panduan Perencanaan dan Pemanfaatan PLTS Atap di Indonesia (2020), tertulis setidaknya tiga manfaat yang dapat diraih jika menggunakan panel surya.

a. Hemat Listrik Memasang panel surya berarti memiliki sumber energi listrik selain listrik PLN. Karena kebutuhan listrik dipenuhi oleh dua sumber, panel surya dapat membantu mengurangi tagihan listrik bulanan dari PLN. Lazimnya, penghitungan pemotongan biaya itu disesuaikan dengan jumlah watt listrik yang dihasilkan panel surya. Pemotongan itu maksimal $65 \%$ dari total daya yang dihasilkan panel surya. Dalam 1 watt listrik dari daya panel surya, pemotongan biaya PLN akan dikurangi maksimal 0,65 watt untuk bulan selanjutnya.

b. Pemanfaatan Energi Terbarukan Pemasangan panel surya berkontribusi dalam pemanfaatan dan pengelolaan energi terbarukan yang tidak akan pernah habis. Sumber daya energi fosil, seperti minyak bumi Indonesia, diperkirakan akan habis pada 2030, maka beralih ke energi modern menjadi langkah strategis untuk ketahanan energi Indonesia. Selain itu, Indonesia tergolong wilayah tropis sehingga paparan sinar matahari mudah dijangkau dan merupakan sumber energi yang amat besar.

c. Ramah Lingkungan Memasang panel surya berkontribusi pada pelestarian iklim dan melawan pemanasan global. Sebab, panel surya dapat mengurangi emisi gas rumah kaca dan ramah lingkungan dan memanfaatkan matahari sebagai energi utamanya. (Gambar 1)

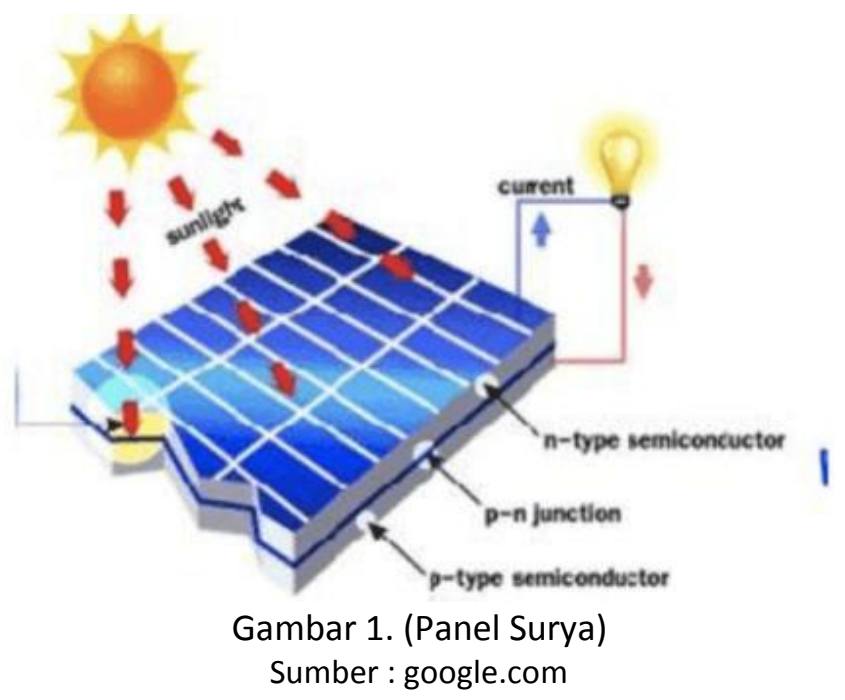

\section{Arsitektur Ekologis}

Ekologi berasal dari bahasa Yunani 'oikos' dan 'logos'. Oikos berarti rumah tangga atau cara bertempat tinggal, dan logos berarti ilmu atau bersifat ilmiah. Ekologi didefinisikan sebagai ilmu yang mempelajari tentang hubungan timbal balik antara makhluk hidup dengan lingkungan di sekitarnya. (Heinz \& Suskiyatno, 2007).

Arsitektur ekologis merncerminkan adanya perhatian terhadap lingkungan alam dan sumber alam yang terbatas. Secara umum, arsitektur ekologis dapat diartikan sebagai penciptaan lingkungan yang lebih sedikit mengkonsumsi dan lebih banyak menghasilkan kekayaan alam. 
Arsitektur tidak dapat mengelak dari tindakan perusakan lingkungan. Namun demikian, arsitektur ekologis dapat digambarkan sebagai arsitektur yang hendak merusak lingkungan sesedikit mungkin. Untuk mencapai kondisi tersebut, desain diolah dengan cara memperhatikan aspek iklim, rantai bahan, dan masa pakai material bangunan. Prinsip utama arsitektur ekologis adalah menghasilkan keselarasan antara manusia dengan lingkungan alamnya.

\section{METODE}

\section{Nett Zero Energy Building}

Nett Zero Energy Building pada bangunan diterapkan pada sistem penggunaan air dan juga pemakaian listrik. Sistem filtrasi grey water menggunakan akar bambu menjadikan air dapat digunakan Kembali sehingga siklus air dapat terus dipelihara dan meminimalisir limbah air yang keluar dari bangunan. Serta pemakaian listrik yang juga dibantu oleh panel surya menggunakan energi panas matahari yang diletakkan di atap pada setiap bangunan dapat membantu penghematan energi listrik dari PLN.

\section{Arsitektur Ekologis}

Penerapan Arsitektur ekologis pada bangunan digunakan pada hutan bambu yang dibuat disekitar bangunan yang ditujukan sebagai pengganti kebutuhan RTH yang kurang khususnya di Jakarta Timur. Bangunan juga memakai material ramah lingkungan yaitu batu roster. Bangunan juga berorientasi kepada arah matahari. Serta mempelajari dari berbagai contoh atau studi kasus.

\section{DISKUSI DAN HASIL}

\section{Hasil dari edge dan rusunawa}

Tapak berlokasi di, Jl. Perumahan Jatinegara Indah No.13, RT.13/RW.12, Jatinegara, Kec. Cakung, Kota Jakarta Timur, Daerah Khusus Ibukota Jakarta 13930. (Gambar 2)

\begin{tabular}{lllll}
\hline KDB & KLB & KB & KDH & KTB \\
\hline $\mathbf{5 0}$ & 3 & 16 & 25 & 60
\end{tabular}

$\begin{array}{lll}\text { Luas Tapak }: 18.000 \mathrm{~m}^{2} & \mathrm{KDH}: 3.578 \mathrm{~m}^{2} \\ \text { KDB } & : 8.945 \mathrm{~m}^{2} & \mathrm{~KB}: 16 \text { Lantai KTB : } \\ \text { KLB } & : 62.615 \mathrm{~m}^{2} & 10.734 \mathrm{~m}^{2}\end{array}$

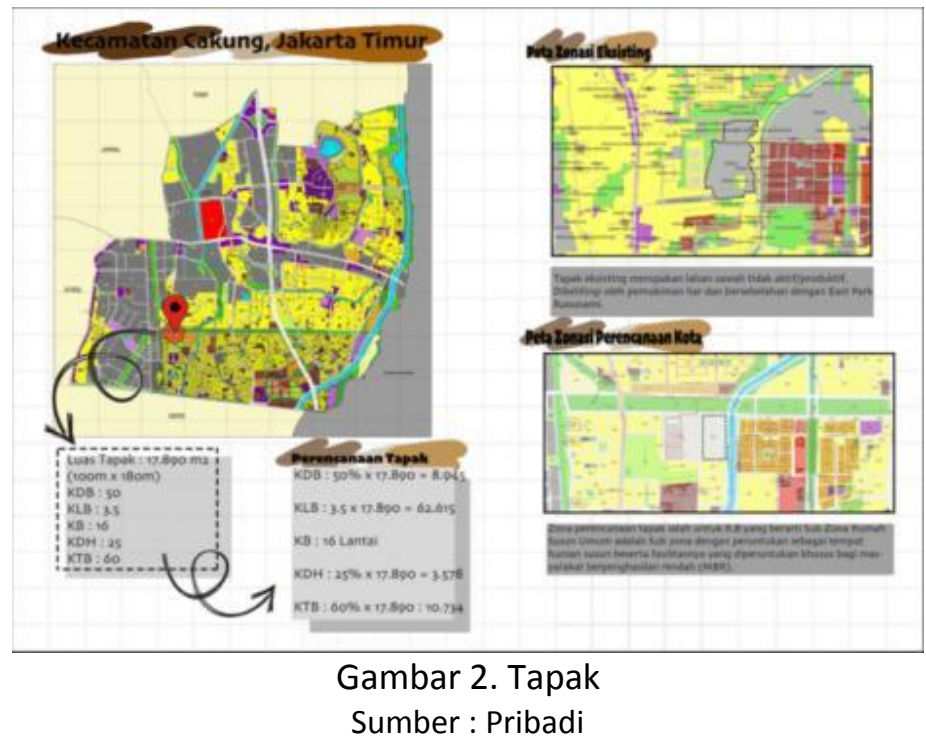


Dari data tersebut, komplek rusunawa cakung direncanakan memiliki fungsi-fungsi sebagai berikut :

1. Fungsi utama bangunan merupakan hunian yang berjumlah : 832 unit terdiri dari tipe unit 24 $\mathrm{m} 2$ dan tipe unit $36 \mathrm{~m} 2$ (kapasitas 3-4 orang).

2. Fasilitas pendukung diletakan pada lantai dasar seperti Posyandu, PAUD, lobi, pelayanan umum, fasilitas niaga, kantin, balai warga, musholla, RPTRA, urban farming pada setiap balkon dan juga area menanam di lantai dasar, dan fasilitas olahraga

Massa bangunan mengikuti arah efisien matahari yaitu utara selatan, hal ini bertujuan untuk memaksimalkan penyebaran cahaya matahari pada setiap unit huniannya serta untuk menciptakan inner courtyard untuk ruang komunal, lapangan dan fasilitas lain yang bersifat umum dan sosial di lantai dasar serta menciptakan dinamika bangunan dan mementingkan jarak antar massa maka massa dimiringkan 15-30 derajat terutama di arah bagian timur agar memiliki RTH yang memadai. (Gambar 3 dan 4).

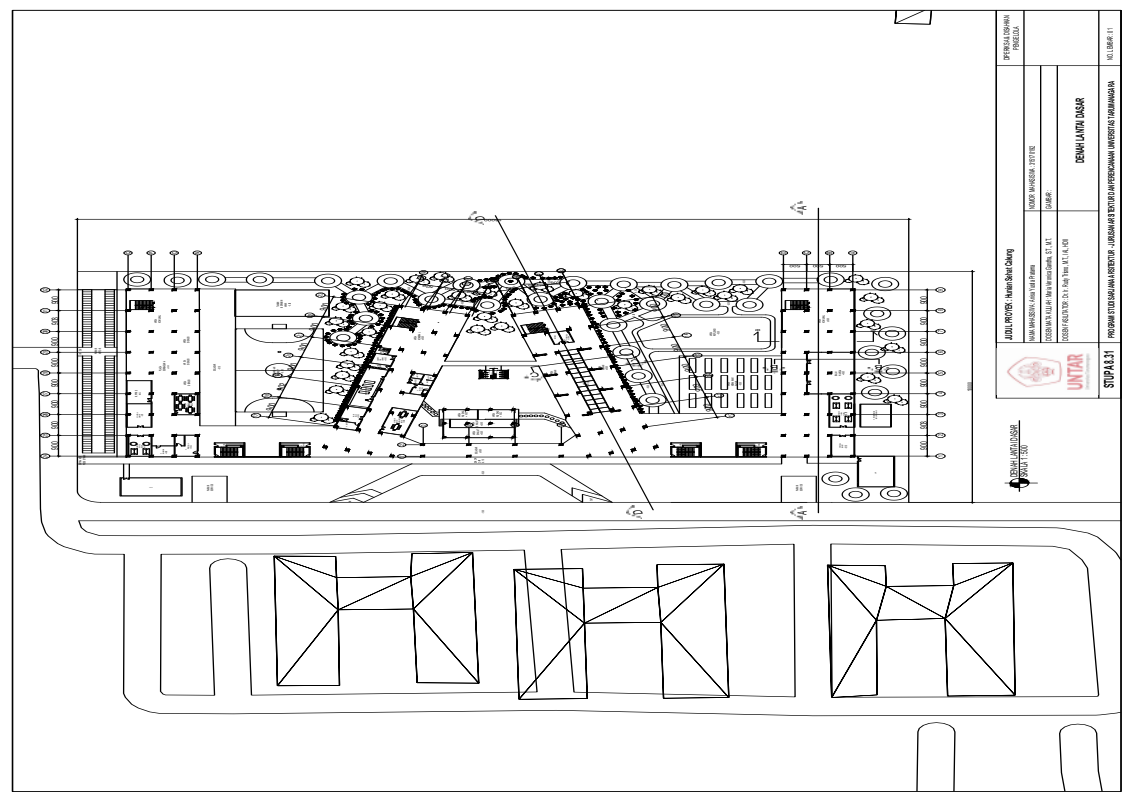

Gambar 3. Site Plan

Sumber : Penulis 2021

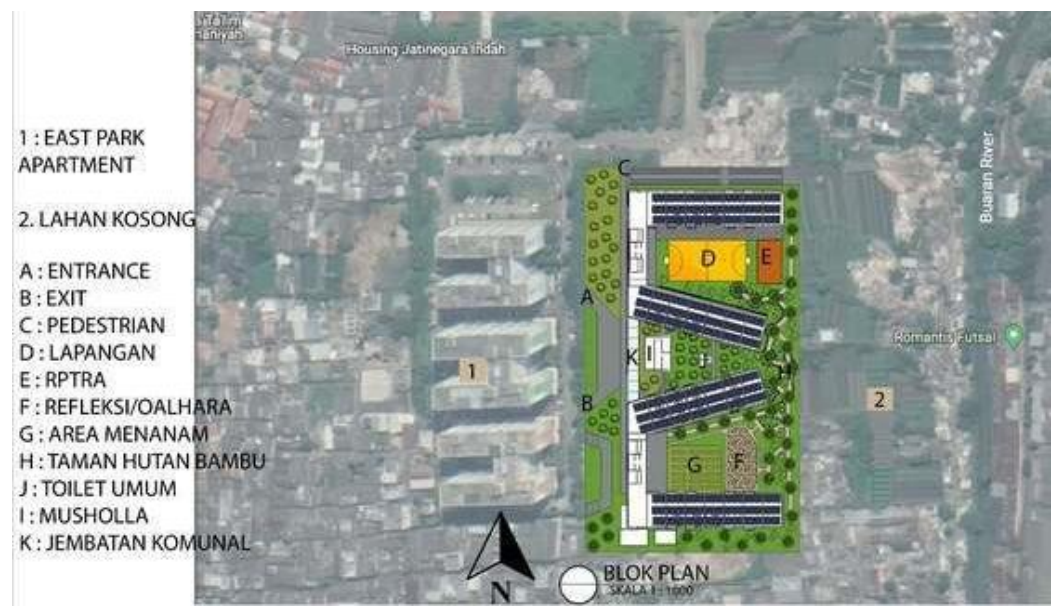

Gambar 4. Blok Plan

Sumber : Penulis 2021 
Bentuk bukaan pada setiap massa diletakkan di arah timur untuk memaksimalkan pencahayaan di lantai-lantai bawah terutama lantai dasar. Bentuk bukaan sengaja dibuat bertrap agar lantai 1 yang digunakan untuk kegiatan komunal dapat memiliki ruang-ruang yang nyaman. (Gambar 4 )

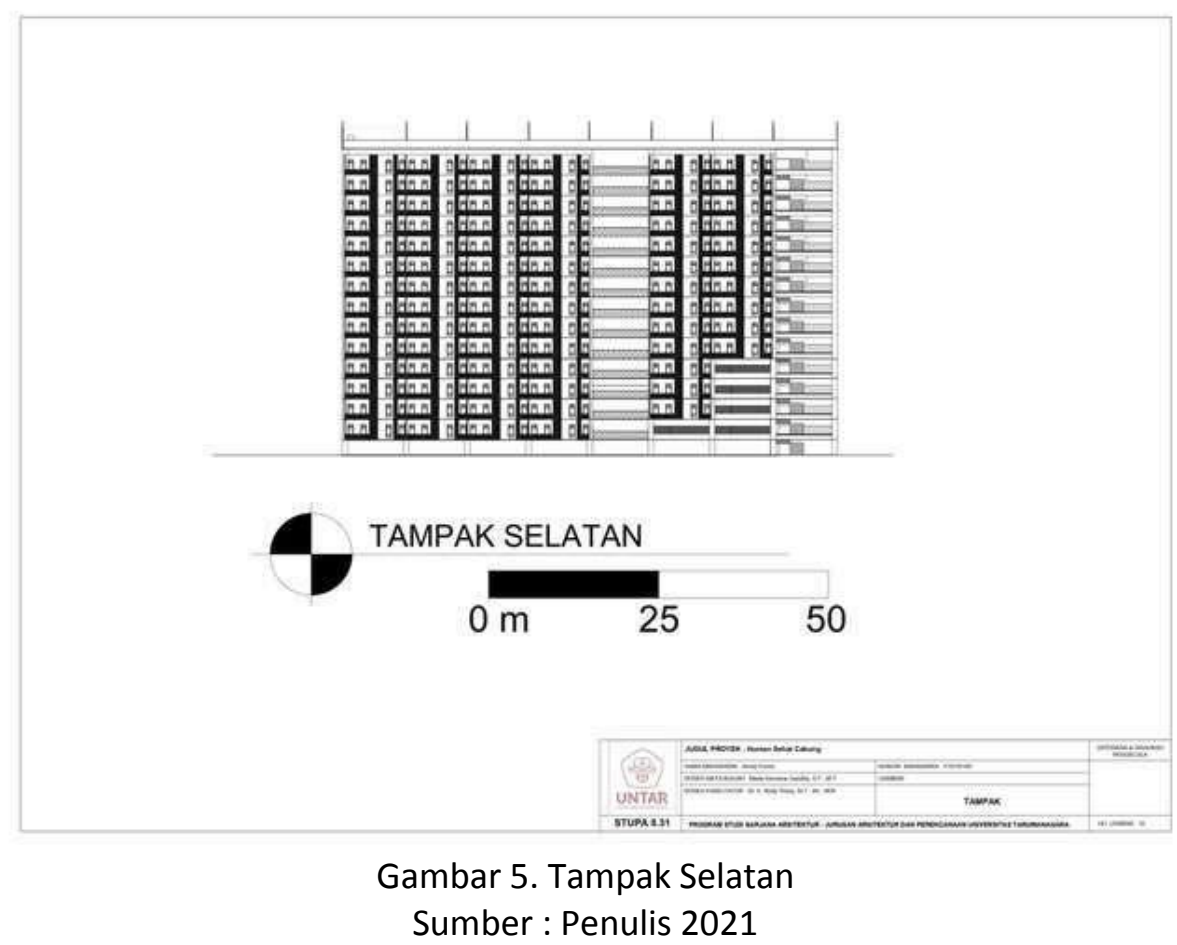

Hunian terdiri dari 2 tipe yaitu unian tipe 36 dan 24. Masing-masing diperuntukan untuk 3-4 orang atau sebuah keluarga. Dilengkapi oleh fasilitas kamar tidur, kamar mandi, ruang keluarga, dapur serta balkon yang jga memiliki media tanam untuk setiap penguin yang berminat dapat memiliki taman/tanaman untuk dapat memenuhi kebutuhan atau membantu mendukung kebutuhan pangan. Hunian 36 dan 24 dalam bentuk kopel yang disetiap lantai memiliki jumlah yang sama antara 36 dan 24. (Gambar 5)

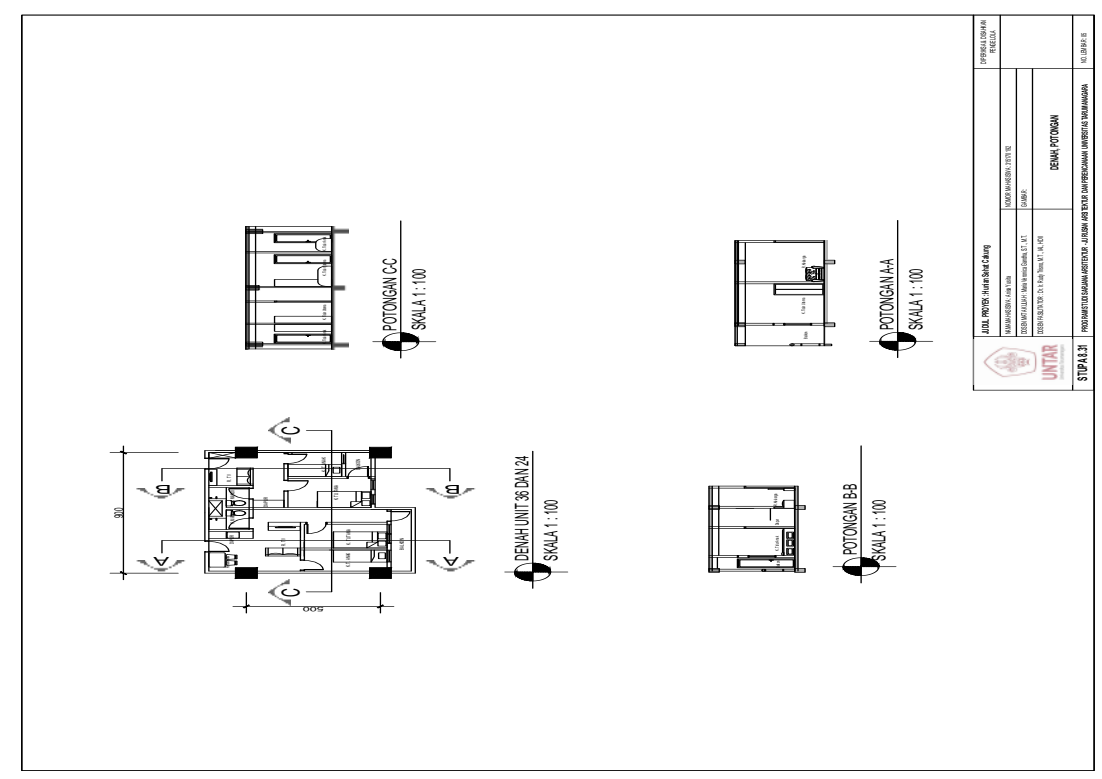

Gambar 6. Denah dan Potongan unit Sumber : Penulis 2021 
Balkon pada setiap unit mengambil tipologi hunian landed. Hunian landed umumnya memiliki halaman belakang. Fungsi dari balkon ini dapat memenuhi kebutuhan akan ruang service seperti ruang jemur pakaian. Ketersediaan wadah bercocok tanam di balkon berupa pipa PVC sebagai media tanam hidroponik diharapkan dapat memicu masyarakat untuk tetap menjaga keseimbangan alam. Selain itu, Balkon merupakan sisi terluar dari setiap unit yang akan menjadi fasad bangunan dan secondary skin secara tidak langsung untuk bangunan menjadikan totalan luasan permukaan yang terbuka atau common area sekitar 5,5 $\mathrm{m}^{2}$. Menjadikan hunian memilki area dengan pencahayaan langsung dan terbias oleh kisi-kisi roster. Memenuhi indikator rumah/hunian yang sehat dan layak huni sesuai UU no.1 tahun 2011. (Gambar 7)

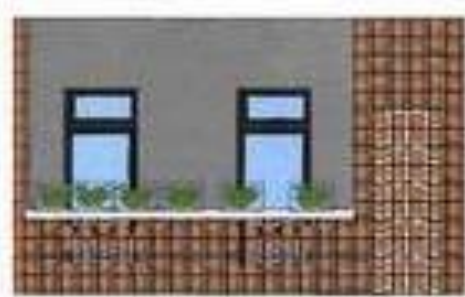

TAMENK DALNON

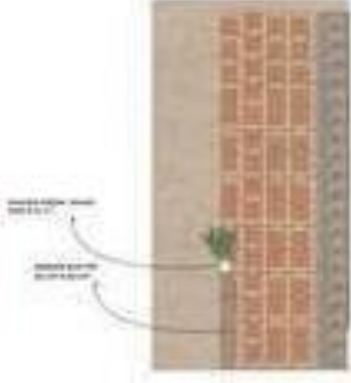

DOTONONS BALXON

Gambar 7. Balkon Unit dinding roster

Sumber : Penulis 2021

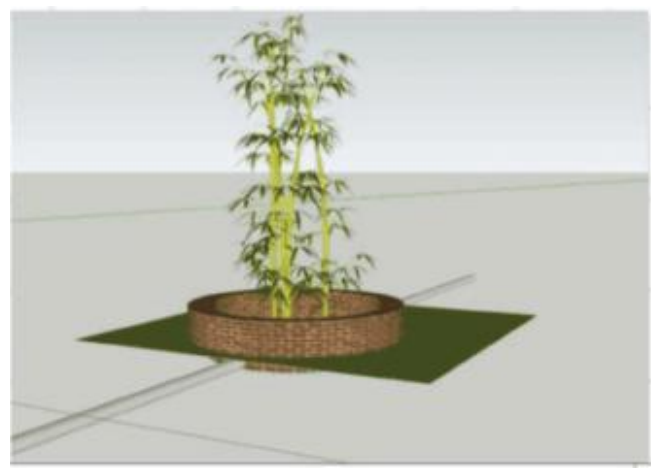

Gambar 8. Rhizofiltrasi Bambu

Sumber : Penulis

Rhizofiltrasi adalah pemanfaatan kemampuan akar tanaman untuk menyerap, mengendapkan, mengakumulasi logam berat dari aliran limbah. Maka dari itu penerapan dari daur ulang air dilakukan menggunakan akar bambu yang tersebar di sekitar tapak yang nantinya akan dialirkan oleh pipa untuk difiltrasi dan juga kembali ke reservoir bawah dan ke riol kota untuk yang sudah tidak layak pakai. Air yang keluar dari bangunan diminimalisir kandungan limbahnya. Akar bambu ini dapat menjadi alternatif menggantikan WTP dengan daya dukung penghijauan juga untuk bangunan.

Desain bangunan yang efisien dalam hal energi mendukung NZEB, digunakan aplikasi Edge untuk menghitung efisiensi energi dan pembuktian penggunaan material pada bangunan berdasarkan sistem yang dipakai di bangunan, seperti sistem air yang efisien, sistem listrik yang efisien dan berkelanjutan, dan material yang ramah lingkungan (Gambar 7). Untuk keempat bangunan dapat mengehmat energi $60-70 \%$ dan air yang diemat sebanyak hampir $40 \%$ dan biaya pembangunan akan kembali dalam jangka waktu 9 tahun dan berkemungkinan lebih cepat karena bangunan ini merupakan bangunan sewa yang dibayarkan setiap bulannya. Jadi 
bangunan dapat Kembali modal dengan jangka waktu paling lama 9 tahun. Selain warga atau penghuni mendapatkan hunian yang sehat dan layak, penghuni juga memiliki biaya sewa yang rendah terkait dengan sistem bangunan yang mengutamakan keberlanjutan khususnya di air yang memakai air daur ulang bamboo dan listrik yang memakai panel surya. Dua faktor ini yang menjadi utama dalam sebuah hunian.

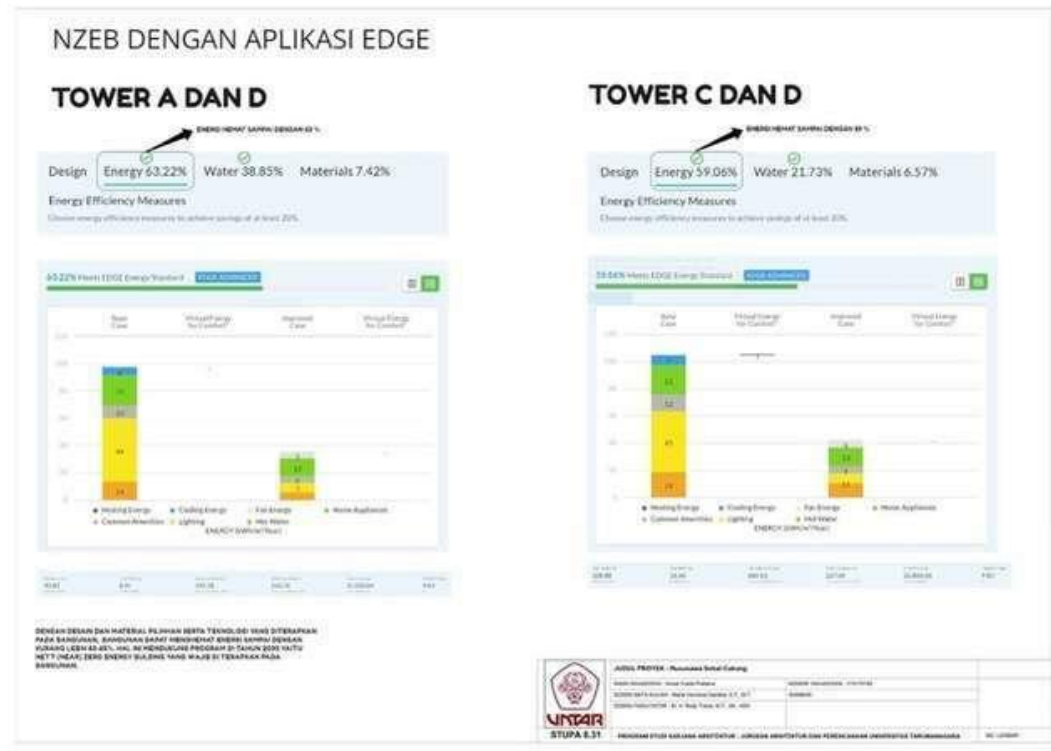

Gambar 8 (Edge)

Sumber : Penulis 2021

Material Fasad dan utama bangunan sebagai cermin dari bangunan yang mendukung nzeb menggunakan material yang rama lingkungan dan penggunaannya mudah dan murah seperti batu roster di setiap sisi fasad dan balkon unit. (Gambar 7)

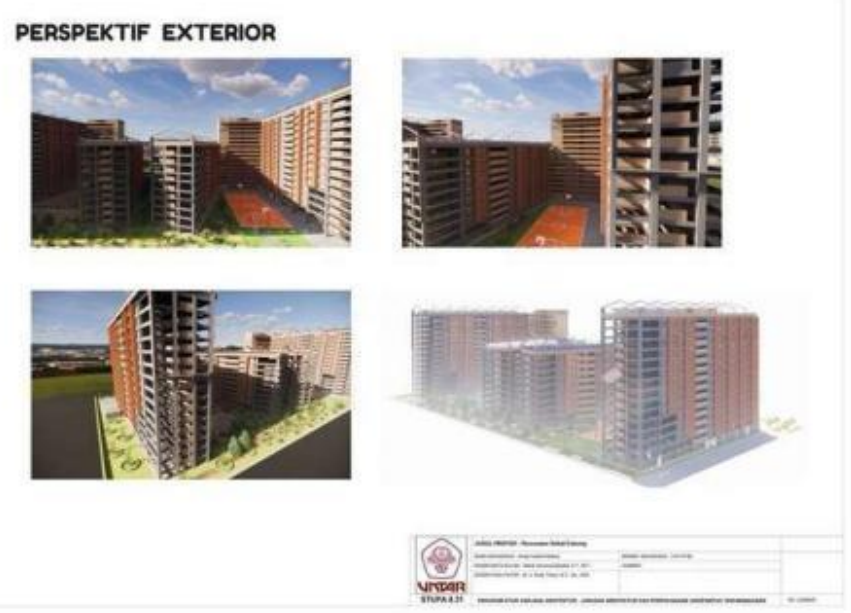

Gambar 9. Perspektif Eksterior

Sumber : Penulis 2021

\section{KESIMPULAN}

Bangunan ini menggunakan metode NZEB yang memperhatikan lingkungan secara system dan ujga keberlangsungannya. Bangunan didesain untuk dapat mengakomodasi kegiatan masyarakat rusunawa yang masuk dalam kategori MBR. Di dalam unit 36 dan 24, terdapat balkon hidroponik yang dapat dijadikan media tanam dan mendukung keberlangsunngan pangan setiap unit. Bangunan juga didesain agar pemakaian energi dapat seefisien mungkin 
serta berkelanjutan, dengan bantuan aplikasi EDGE untuk menentukan besaran energi dan besaran air yang dihemat oleh bangunan. Rata-rata penghematan energi adalah sebesar 60-65 $\%$, sementara air dapat dihemat hingga $40 \%$, sehingga bangunan dapat dikategorikan sebagai bangunan hemat energi.

\section{Saran}

Hunian ke depannya sudah seharusnya memperhatikan segi keselamatan dan kesehatan penghuni, terutama memberi fokus kepada masyarakat MBR. Pencahayaan, dan pengudaraan alami harus menjadi nomor satu dalam merancang hunian masa depan, dikarenakan memiliki hunian sehat menjadi hak setiap orang. Selain itu, membangun sebuah bangunan harus memperhatikan dari segi lingkungan, upayakan agar bangunan tidak terlalu membebani lingkungan dengan mendesain secara berkelanjutan.

\section{Referensi}

Adhitya Akbar. (n.d.). PORTAL STATISTIK SEKTORAL PROVINSI DKI JAKARTA. Retrieved from BERAPA KEPADATAN PENDUDUK DKI JAKARTA SAAT INI?: https://statistik.jakarta.go.id/berapa-kepadatan-penduduk-dki-jakarta-saat-ini/

Direktorat Jenderal Energi Baru, Terbarukan dan Konservasi Energi. (2020). Pelatihan Net Zero Healthy Building bersama GBCl. Jakarta, Jakarta, Indonesia. (n.d.).

Frick, H. (2007). Dasar-dasar Arsitektur Ekologis. Yogyakarta.

Heinz , F., \& Suskiyatno, B. (2007). Dasar-Dasar Arsitektur Ekologis. Yogyakarta: Kanisius.

Magdalena, E., \& Tondobala, L. (2016). IMPLEMENTASI KONSEP ZERO ENERGY BUILDING (ZEB) DARI PENDEKATAN ECO-FRIENDLY PADA RANCANGAN ARSITEKTUR. MEDIAMATRASAIN, 13(1), 15.

Purwoto, B. H., Jatmiko, Alimul , M., \& Huda, I. F. (n.d.). EFISIENSI PENGGUNAAN PANEL SURYA SEBAGAI SUMBER ENERGI ALTERNATIF. Emitor: Jurnal Teknik Elektro, 18(1), 5.

Soeranto, Dwityo A. (2020, Desember). Dinamika Pengembangan Perumahan Skala Besar. (D. A. Soeranto, P. Marpaung, \& C. R. Situmorang, Eds.) Jakarta, Jakarta, Indonesia.

Wilfridus Setu Embu. (n.d.). Merdeka.com. Retrieved from merdeka.com: https://www.merdeka.com/uang/mampukah-jakarta-bisa-sediakan-hunian-murah.html https://www.kompasiana.com/satria_wijayakusuma/5b0d7571dd0fa80c96342797/mengata si-permasalahan-keterbatasan-lahan-perumahan-permukiman-di-dki-jakarta?page=all 